\title{
New Host Materials Containing Carbazole and Naphthyl Moieties for Green Dopant in Phosphorescence Organic Light-Emitting Diodes (OLEDs)
}

\author{
Dong-Ha Kim, ${ }^{\dagger}$ Cheol-Kwang Hong, ${ }^{\dagger}$ Phil Ho Lee, ${ }^{*}$ and Youngjin Kang ${ }^{*}$ \\ National Research Laboratory for Catalytic Organic Reaction \& Department of Chemistry and Division of Science Education, \\ Kangwon National University, Chincheon 200-701, Korea."E-mail: kangy@kangwonac.kr; phlee@kangwon.ackr \\ "Electronic Material Development Team, Corporate R\&D Center, LUDIS Co. Ltd., Kyninggi 463-420, Korea \\ Received Angust 13, 2008
}

Key Words : Carbazole host, Energy transfer, Ir(ppy) $)_{3}$ OLEDs, Phosphorescence

Much effort on the development of new host materials has been devoted to increase the emission efficiency of organic light-emitting diodes (OLEDs). ${ }^{1}$ In particular, the use of phosphorescent molecules as guest emitters, which harvests both singlet and triplet excitons, leads to internal quantum efficiency $\left(\eta_{\text {isi }}\right)$ approaching $100 \%{ }^{2}$ Energy transfer from a host to a dopant in OLEDs can result in high extemal quantum efficiency $\left(\eta_{\text {exi }}\right)$. Therefore, the development of suitable hosts for blue, green and red phosphorescent emitters has been one of the major issues in the field of OLEDs. In general, host materials should have a higher triplet energy than that of the dopant molecules due to the energy transfer from the host to the guest while prohibits the energy transfer of triplet excitons from the guest to the host material. ${ }^{3}$ From the point of this consideration, carbazole derivatives are often use as host materials, because they have high triplet energies ( $2.9 \mathrm{eV}$ or less). ${ }^{4}$

Polyaromatic compounds bearing naphthyl groups have formed an important class of highly efficient and stable bluelight emitting materials. ${ }^{3}$ It has been suggested that nonplanar derivatives of naphthalene due to steric factors may hinder close packing and improve the device performance; hence, the electroluminescence (EL) polyaromatic compounds bearing naphthyl groups have been designed on the basis of this principle. ${ }^{6}$ During our ongoing efforts on the development of emitting materials and host for phosphorescence OLEDs, we have observed that naphthyl derivatives linked by 9-ethylcarbazole unit as a core, such as 3,6-di(1naphthyl)-9-ethylcarbazole (1-DNEC) and 3,6-di(2-naphthyl)-9-ethylcarbazole (2-DNEC), have high thermal stability, reversible electrochemical behaviors and larger band gap compared to those of other carbazole derivatives. ${ }^{7}$ These facts have prompted us to investigate electroluminescent (EL) characteristics of both compounds. Herein, we discuss electroluminescent characteristics and device data for OLEDs employing both 1-DNEC and 2-DNEC as host.

We fabricated multilayer devices with the configuration of ITO/NPB $(30 \mathrm{~nm}) /$ (device I) 1-DNEC and 2-DNEC (device 2): Ir(ppy) $(45 \mathrm{~nm}: 3 \%) / \mathrm{Alq}_{3}(25 \mathrm{~nm}) / \mathrm{LiF}(2 \mathrm{~nm}) / \mathrm{Al}$. The layers of the device consist of ITO (indium-tin-oxide) as the anode, NPB ( $N, N^{\prime}$-di-I-naphythyl-N,N'-diphenyl-byphenyl4,4-diamine) as the hole transporting layer, I-DNEC or 2DNEC as host, 3\%-Ir(ppy) 3 (ppy $=2$-phenylpyridine) as the emitter, $\mathrm{Alq}_{3}(\mathrm{q}=8$-hydroxyquinolate) as the electron transporting layer, $\mathrm{LiF}$ as the electron injection layer, and $\mathrm{Al}$ as the cathode, respectively (Figure 1). In this study, we chose $\operatorname{Ir}(p p y)_{3}$ as the emissive material, which is a prototypical dopant for green OLEDs. The electroluminescence spectra of all devices consist only of green emission $\left(\lambda_{\max }=458 \mathrm{~nm}\right)$ from $\operatorname{Ir}(\mathrm{ppy})_{3}$ without any emissions from the host and $\mathrm{Alq}_{3}$,
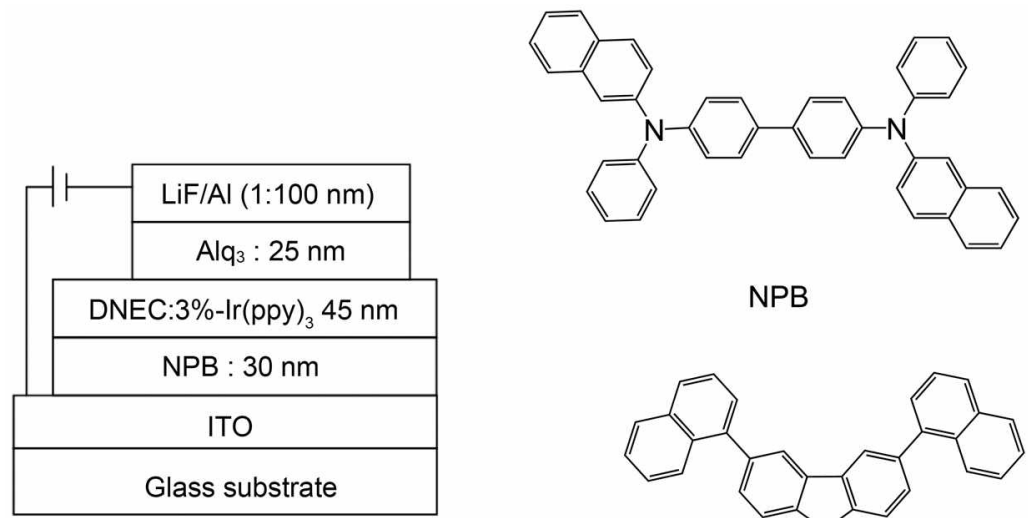

NPB

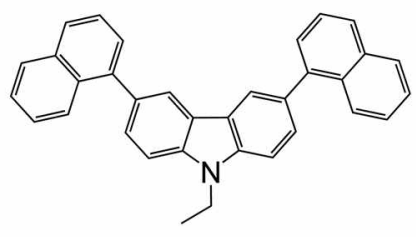

1-DNEC

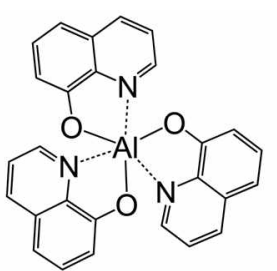

$\mathrm{Alq}_{3}$

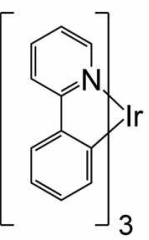

$\operatorname{Ir}(\text { ppy })_{3}$

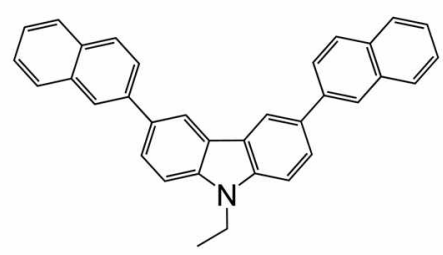

2-DNEC

Figure 1. Device structure and molecular structures used in this study. 


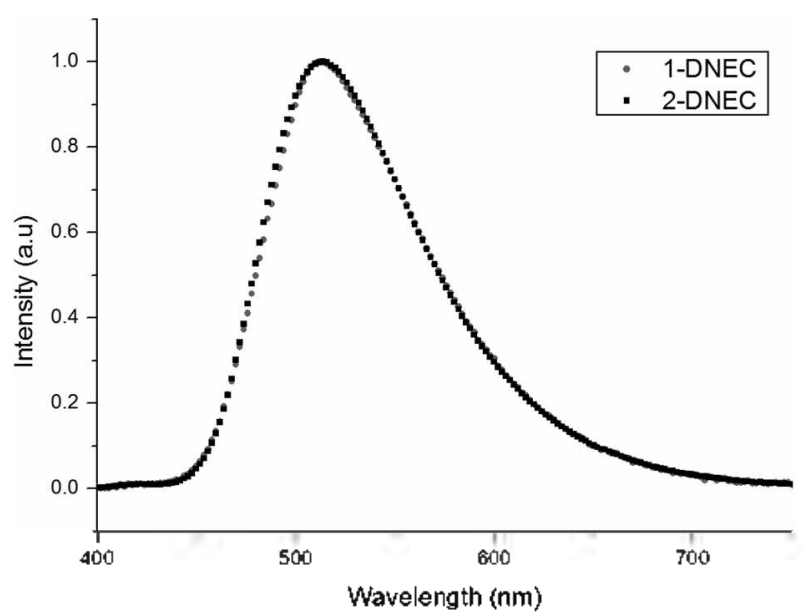

Figure 2. EL spectra of device 1 and 2 (Device 1: ITO/NPD/1DNE C: $\operatorname{Ir}\left(\mathrm{ppy}_{3} / \mathrm{Alq}_{3} / \mathrm{LiF}-\mathrm{Al}\right.$; Device 2: ITO/NPD/2-DNEC: Ir(ppy)/ $/$ $\mathrm{Alq}_{3} / \mathrm{LiF}-\mathrm{Al}$ ).

moreover the EL spectra of these devices do not change significantly with variation of the applied voltage, as shown in Figure 2. The emission observed in the EL device support the suggestion that complete energy transfer from the host to the dopant occurs at the $3 \mathrm{wt} \%$-doped level. To be a good host material, a lower occupied molecular orbital energy level $(\mathrm{HOMO}$ ) and a higher unoccupied molecular orbital energy level (LUMO) are required for ease of charge injection from neighboring layers. The HOMO energy levels were deduced from their oxidation potentials measured by cyclic voltammetry (CV), while the LUMO energy levels were estimated based on the HOMO energy levels and the optical band gaps obtained from the absorption spectra. In the CV measurement, they showed reversible oxidation waves, indicating all of these naphthyl-containing carbazole derivatives are in stable reduced forms under the electrochemical condition. The estimated HOMO energy levels are -5.63 , and -5.54 for 1-DNEC and 2-DNEC, respectively, as shown in Figure 3 inset. Although the conjugated systems are structurally different, the HOMO energy levels of both

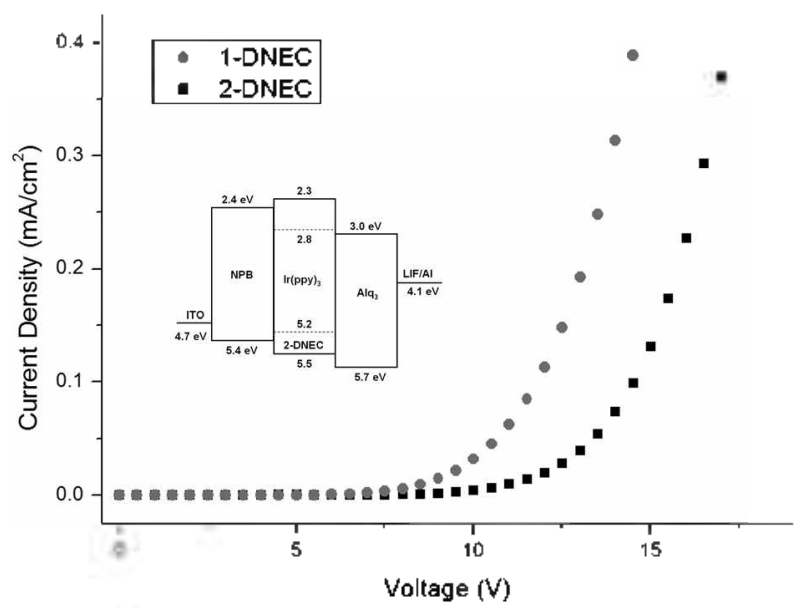

Figure 3. Voltage versus current density characteristics (inset: proposed energy level diagram). compounds are almost the same and slightly higher than that of CBP. This observation suggests that their hole injection ability is strengthened, which would reduce the recombination zone to be confined within the emission layer. In addition, a wide singlet energy gaps $\left(E_{\mathrm{g}}=c a 3.3 \mathrm{eV}\right)$ of both compounds are expected for a wide triplet energy. Enlarged energy gap would maintain the excitations within the guest. The operating voltages (defined as $1 \mathrm{~mA} / \mathrm{cm}^{2}$ ) of the device 1 and device 2 are observed at $6.5 \mathrm{~V}$ and $8.5 \mathrm{~V}$ respectively, which are fairly low values as compared to those of other devices using CBP as a host (Figure 3 ). ${ }^{8}$ The feasibility of carrier injection in each layer is considered one of the most important factors in detemining the operating voltage." Effective carrier injection from either hole transporting layer or electron transporting layer to emissive layer gives rise to decreasing driving voltages in OLEDs. Therefore, wellmatched energy gap of each layer is the most important in order to fall off driving voltage.

The current $v s$ voltage and current density $v s$ luminescence characteristics are depicted in Figure 3 and Figure 4, respectively. A maximum brightness of $4165 \mathrm{~cd} / \mathrm{m}^{2}$ at $14 \mathrm{~V}$, luminance efficiency of $1.58 \mathrm{~cd} / \mathrm{A}$ and extemal efficiency of $0.59 \%$ at $12 \mathrm{~V}$ were achieved for device 1 . Commission Intemationale de l'Eclairage coordinates, $x$ and $y$, were calculated to be 0.279 and 0.497 at $11 \mathrm{~V}$. To compare with a 1-DNEC host, the device 2 using 2-DNEC as a host was also fabricated under the same condition and its electrical characteristics were measured. A maximum brightness of $3036 \mathrm{~cd} / \mathrm{m}^{2}$ at $18 \mathrm{~V}$, luminance efficiency of $1.51 \mathrm{~cd} / \mathrm{A}$ and extemal efficiency of $0.56 \%$ at $12 \mathrm{~V}$ were achieved. Device 1 shows higher efficiency than in device 2. This fact suggests that the position of the naphthyl on the carbazole could be important factors in achieving high electroluminescent efficiency. With increasing current density, the external quantum efficiency of devices $I$ and 2 were gradually decreased. Similar results have been reported previously, and are attributed to the increase of triplet-triplet annihilation of exciton at high voltage levels. ${ }^{10}$ The low efficiency in the EL device is perhaps due to several reasons. One is the purity of host. The other is poor recombination ratio of hole and

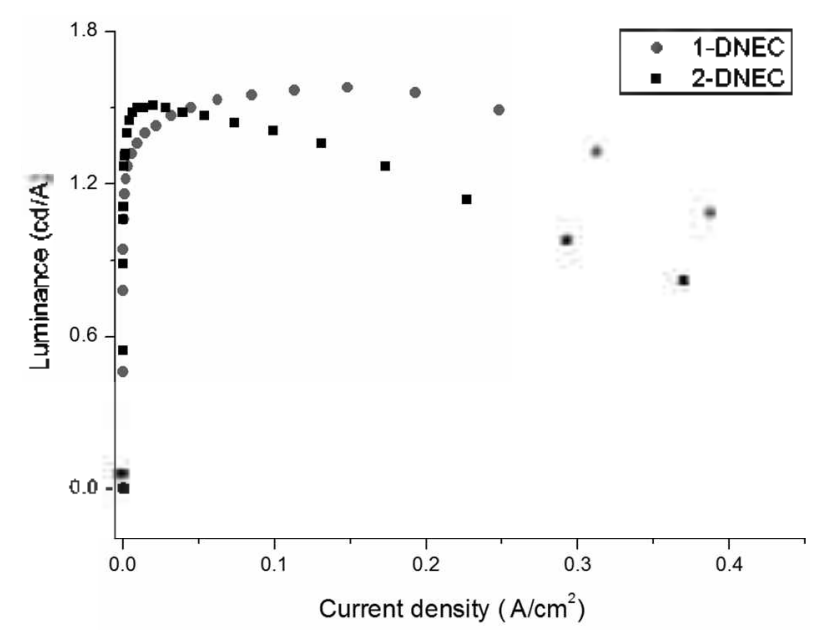

Figure 4. Luminance versus current density characteristics. 
Table 1. Electroluminescent data using 1-DNEC and 2-DNEC as host

\begin{tabular}{ccccc}
\hline Device & $\begin{array}{c}\text { Luminescence } \\
\left(\mathrm{Cd} / \mathrm{m}^{2}\right) \\
\text { at } 14 \mathrm{~V}\end{array}$ & $\begin{array}{c}\text { Operating } \\
\text { Voltage } \\
(\mathrm{V} /)^{\circ}\end{array}$ & $\begin{array}{c}\text { External } \\
\text { Quantum } \\
\text { Efficiency }(\%)\end{array}$ & CIE $\left(x, y^{y}\right)$ \\
\hline 1 & 4165 & 6.5 & 0.59 & $(0.279,0.497)$ \\
2 & 1062 & 8.5 & 0.56 & $(0.284,0.504)$ \\
\hline
\end{tabular}

"The operating voltages in all cases were defined as $1 \mathrm{~mA} / \mathrm{cm}^{2}$

electron in emissive layer. As shown in Figure 3, the HOMO level of Ir(ppy $)_{3}$ is located only slightly above the HOMO of DNEC hosts, thus Ir(ppy) $)_{3}$ can act as a shallow trap for positive charge carriers. Therefore, the positive carriers will reside in the host as well as in the guest. It inhibits efficient charge recombination on the guest and thus BCP $(2,9-$ dimethyl-4,7-diphenyl-9,10-phenanthroline) needs to be used as hole blocking layer because of its well-known low HOMO energy. Utilizing BCP as a hole blocking layer will improve the efficiency of both devices.

Although the efficiency of both device is low, we believe that high efficiency should be achieved by changing the concentration of Ir(ppy). Energy transfers, in general, are quite sensitive upon doping concentration, complete energy transfers tend to emerge at higher doping levels. In addition, the purity of host material is also important to achieve high efficiency. Due to the lack of purification apparatus, we have conducted EL experiment using low purity host. Therefore, we believe that the improvement of host purity, addition of hole blocking layer and the increase of dopant doping level make it possible for the device to show high efficiency.

In summary, we have fabricated two OLEDs successfully using new host materials (carbazole and naphthyl derivatives) and demonstrated electroluminescent characteristics. Different position of naphthyl unit has influence on the efficiency of EL as well as HOMO energies. These results imply that the substituents play a key role in improvement of EL efficiency. Pioneering impact of this study lies in its commencement of host development using carbazole and naphthyl unit. We believe that it is highly recommended to put consistent effort in the development of derivatives of this kind. Further improvement and optimization of EL devices fabricated by using these compounds are being investigated in our laboratory.

\section{Experimental Section}

The molecular structure and device structure in this study are presented in Figure 1. The 1-DNEC and 2-DNEC were synthesized according to the previous method by the reaction of 3,6-dibromo-9-ethylcarbazole and corresponding indium naphthylenide? Electroluminescent devices were fabricated by vapor depositing organic layers onto a glass substrate precoated with indium-tin oxide (ITO) with a sheet resistance of $10 \Omega / \mathrm{cm}$. The substrate was washed, dried, and then immediately loaded into the evaporation system. The organic and metal cathode layers were grown in the chamber at $1 \times 10^{-7}$ and $6 \times 10^{-7}$ Torr without breaking vacuum, respectively. The deposition process started with a $30 \mathrm{~nm}$ thick hole-transporting layer of NPB, followed by a $45 \mathrm{~nm}-$ thick layer of Irppy 3 -3\%: 1-DNCE or 2-DNCE (dopant: host), a $25 \mathrm{~nm}$ thick electron-transporting layer of tris(8hydroxylquinolinato)aluminum(III) $\left(\mathrm{Alq}_{3}\right)$, and finally a metallic $\mathrm{LiF} / \mathrm{Al}$. The emission area of the devices was 9 $\mathrm{mm}^{2}$. After deposition, the device was measured immediately without encapsulation. The EL spectra and currentvoltage-luminescence characteristics were measured with a Minolta CS 1000 photometer and a computer-controlled DC power supply under ambient conditions. The emission area of the devices is $0.09 \mathrm{~cm}^{2}$ as determined by the overlap area of the anode and the cathode.

Acknowledgments. This work was supported by the Korea Science and Engineering Foundation (KOSEF) through the National Research Laboratory Program funded by the Ministry of Science and Technology (No. M10600000203-

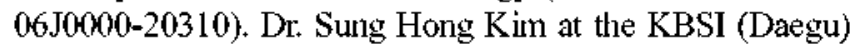
is thanked for obtaining the MS data.

\section{References}

I. (a) Ren, X.; Li. J.; Holmes. R. J.; Djurovich. P. I.; Fortest, S. R.; Thompson, M. E. Chem. Mater. 2004, 16, 4743. (b) Holmes, R. J.; Forrest, S. R.; Tung, Y.-J.; Kwong, R. C.; Brown, J. J.; Garon, S.; Thompson, M. E. Appl. Phys. Lett. 2003, 82, 2422. (c) Adachi, C.; Baldo, M. A.; Forrest, S. R.; Thompson, M. E. Appl. Phys. Lett. 2000, 77,904

2. (a) Jung, S. O.; Kang, Y.; Kim, H.-S.; Kim, Y.-H.; Yang, K.; Kwon, S.-K. Bull. Korean Chem. Soc. 2003, 24, 1521. (b) Adachi, C.; Baldo, M. A.; Forrest, S. R.; Thompson, M. E. J. Appl. Phys. 2001, 90, 4058. (c) Ikai, M.; Tokito, S.; Sakamolo, Y.; Suzuki, T.; Taga, Y. Appl. Phys. Lett. 2001, 79, 156. (d) Adachi, C.; Lamansky, S.; Baldo, M. A.; Kwong, R. C.; Thompson, M. E.; Forrest, S. R. Appl. Phys. Lett. 2001, 78, 1622.

3. (a) Nazeeruddin, Md. K.; Humphry-Baker, R.; Berner, D.; Rivier, S.; Zuppiroli, L.; Graetzel, M. J. Am. Chem. Soc. 2003, 125, 8790. (b) Tanaka, I.; Tabata, Y.; Tokito, S. Chem. Phys, Lett, 2004, 400, 86. (c) Kook, S.-K. Bull. Korean Chem. Soc. 2007, 28, 2409. (d) Roh, S.-G.; Baek, S. N.; Kim, Y. H.; Kim. H. K. Bull. Korean Chent. Soc. 2007, 28, 1249.

4. (a) Adamovich, V.; Brooks, J.; Tamayo, A.; Alexander, A. M.; Djurovich, P. I.; D'Andrade, B. W.; Adachi, C.; Forresi, S. R, Thompson, M. E. New J. Chem. 2002, 26, 117I. (b) Thoms, T. Okada, S.; Chen, J.-P.; Furugori, M. Thin Solid Films 2003, 436, 264. (c) Justin, K. R.; Lin, J. T.; Tao, Y.-T.; Ko, C.-W. J. Am. Chem. Soc. 2001, 123,9404.

5. Etori, H.; Jin, X. L.; Yasuda, T.; Mataka, S.; Tsutsui, T. Sy $n$ h. Met. 2006, 156,1090 .

6. (a) Bonvallet, P. A.; Breitkreuz, C. J.; Kim, Y. S.; Todd, E. M.; Traynor, K.; Fry, C. G; Ediger, M. D.; McMahon, R. J. J. Org. Chem. 2007, 72, 1005I. (b) Lee, J.-H.; Ho, Y.-H.; Lin, T.-C.; Wu, C.-F. J. Electrochen. Soc. 2007, 154, J226. (c) Tang, H.; Li, Y.; Wang, X.; Wang, W.; Sun, R. Jpn. J. Appl. Phss. 2007, 46, 1722 .

7. Lee, W.; Kang, Y.; Lee, P. H. J. Org. Chem, 2008, 73, 4326.

8. Jung, S.; Kang, Y.; Kim, H.-S.; Kim, Y.-H.; Lee, C.-L.; Kim, J.-J.; Lee, S.-K.; Kwon, S.-K. Etr. J. Inorg. Chent. 2004, 17,3415.

9. Guan, M.; Chen, Z.; Bian, Z.; Liu, Z. W.; Gong, Z. L.; Baek, W.; Lee, H. J.; Huang, C. H. Org. Electron. 2006, 7, 330.

10. Baldo, M. A.; Adachi, C.; Fortest, S. R. Phys, Rev: B 2000, 62, 10967. 